\title{
THE DIFFERENTIAL DIAGNOSIS OF COMA
}

\author{
By Patrick J. SweEney, M.D., M.R.C.P.I., M.R.C.P. \\ Lately First Assistant, Department of Medicine, Royal Victoria and West Hants Hospital, Bournemouth
}

The difficulties in the diagnosis of the unconscious state are known to all. As an adequate history is so often lacking, physical examination must be exhaustive and the first essential is the accurate assessment of the degree of unconsciousness present. The term coma implies a state of unconsciousness from which the patient cannot be roused. Painful stimuli, e.g., firm pressure over the supraorbital foramen, have no effect. The corneal and pupillary reflexes, muscle tone, and the deep reflexes, are frequently abolished. Milder degrees of coma exist where, although the patient is unconscious, pupillary and corneal reflexes are obtained and painful stimuli provoke a reaction. Stupor indicates a state of partial loss of consciousness where the response to external stimuli is markedly diminished and is also characterized by a tendency to resist interference and to catalepsy. It is extremely important to record carefully the degree of unconsciousness present at the initial examination of the patient, in order to establish a base line and follow the course of the condition. The slow development of cerebral compression following a head injury, e.g. ruptured middle meningeal artery, illustrates the importance of this point. Particular attention must therefore be paid to the pupils, fundi, muscle tone, deep reflexcs, plantar responses, pulse rate and temperature. Other points such as the odour of the breath, the type of breathing etc., are well known to all, and will not be stressed here.

The common causes of comatose, semi-comatose and stuporose states will now be considered.

\section{Trauma}

Unconsciousness following concussion is shortlived, but prolonged coma may follow cerebral contusion or laceration. Bleeding from the nose or ears, or subconjunctival haemorrhage, may indicate a fractured skull and the need for radiography. Lumbar puncture should be performed in all cases, as the presence of blood in the cerebrospinal fluid is often unsuspected.

It should be remembered that an alcoholic aroma is no guarantee that a cerebral injury has not occurred. Coma from a slowly developing subdural haematoma, the result of rupture of cortical veins, is often difficult to differentiate from a brain tumour, especially as the original injury may have been trivial and disregarded by the patient.

\section{Case Report}

A male, aged 45, admitted March 30 , 1948 with a history of severe headache for a week.

Examination revealed a semicomatose patient. Pupils equal and light reactive, fundi normal, muscle tone increased and reflexes generally increased. No neck rigidity or fascial weakness. Bilateral extensor plantar response.

Heart and lungs normal. Blood-pressure 120/70. Rulse 62. Temperature $98^{\circ}$.

Lumbar puncture revealed a clear fluid under a pressure of $280 \mathrm{~mm}$. Slight increase of protein, and 10 white cells per cu. mm., mostly lymphocytes. Two hours after the lumbar puncture, the patient was sitting up in bed, quite rational, feeling well, but rather euphoric and unduly talkative.

During the next three days, his condition remained unchanged, but he complained of occasional headache and was subject to periods of drowsiness. No abnormal signs could be detected in the nervous system.

On April 5, 1948, the lower limb reflexes were found to be brisker on the left side, and the left plantar response extensor. (The first localizing signs.)

On April 7, 1948, he again became unconscious, with twitching and rigidity of all extremities. Both plantar responses were extensor. Blood sugar and blood calcium normal. Repeat lumbar puncture revealed a clear fluid under slightly increased pressure, with a marked increase of protein, and 29 white cells per cu. mm. The fundi remained normal.

He was seen by a surgical colleague who suggested a diagnosis of right subdural haematoma. Ventriculography was carried out with negative result, and the patient died on April 10, 1948.

Post mortem examination revealed a soft vascular tumour in the right occipital lobe, which on section proved to be a spongioblastoma of varied pleomorphic structure.

Periods of drowsiness, stupor or coma from which recovery takes place with subsequent relapse, and localizing pyramidal tract signs of the type mentioned in this case, together with a slow pulse, are considered typical features of a subdural haematoma. Cellular increase in the cerebro-spinal fluid is not a feature, but is more 
suggestive of cerebral abscess or tumour, as in the case described.

\section{Intoxications and Poisons}

During the past year, 40 per cent. of the comatose patients admitted to the medical wards of this hospital were suffering from, in the following frequency, carbon monoxide, barbiturate and aspirin poisoning. An indication, perhaps, of present day conditions, when coupled with the fact that alcoholic coma was not encountered.

Carbon monoxide poisoning is usually obvious from the history. It should be noted however, that the typical cherry-red colour of the face and lips is not always present, and that even a mild degree of carbon monoxide poisoning may precipitate cardiac failure and pulmonary oedema with resultant coma, in a patient with pulmonary or cardiac disease. A simple clinical test for carboxyhaemoglobin is to dilute one drop of the patient's blood in a test tube of water, and compare with a control from a normal person. A carmine tint will be evident if there is much carboxyhaemoglobin present. A diagnosis of barbiturate or aspirin poisoning is more difficult. Deep coma, sweating and extensor plantar responses are common to both. A raised temperature, cyanosis and pulmonary oedema are typical findings in barbiturate poisoning, as exemplified in the following case.

\section{Case Report}

A female aged 35 was admitted on October I9, 1947. She was found unconscious in her flat with a bottle of nembutal capsules beside her. There were three capsules left out of a possible original total of twenty-five.

She was deeply comatose, i.e., ' corneal and pupillary reflexes absent, deep reflexes absent, limbs flaccid, no response to painful stimuli. Bilateral extensor plantar responses. Cyanosed. Moist skin. Breathing noisy and bubbly with moist sounds throughout both lungs, obscuring the heart sounds. Blood pressure 1 10/90. Pulse 90. Temperature $100^{\circ}$. With large doses of coramine and picrotoxin intravenously, the pupillary reflexes returned after three hours, but it was three days before the patient became fully conscious and rational.

If no history is available, barbiturates can be detected in the urine and cerebrospinal fluid, using Millon's reagent.

Aspirin poisoning is characterized by evidence of vomiting, profuse sweating, and deep breathing which may resemble the air hunger of diabetic coma. The ferrichloride test for salicylates in the urine is positive. Where alcoholic coma is suspected, a careful physical examination is necessary in order to exclude other medical or surgical causes of coma. To quote Walshe, 'alcoholic coma is diagnosed most safely by a process of exclusion.' Opium poisoning is seldom seen nowadays. Its chief features are a cold, clammy skin, a slow respiration rate, and pin-point pupils. In all cases of suspected poisoning, gastric lavage should be performed and the gastric contents kept for analysis. Lead poisoning is a rare cause of coma, and as a rule a preceding history of vomiting, abdominal colic, headache and constipation will be obtained. If suspected, the gums should be examined for the well known blue line, the blood for punctate basophilia and evidence of anaemia, which may be haemolytic in type, and the urine analysed for lead.

\section{Gerebral Vascular Lesions}

Coma resulting from cerebral haemorrhage, embolism or thrombosis is characterized by hemiplegia in the great majority of cases. Usually there is conjugate deviation of the head and eyes towards the side of the lesion, the paralysed cheek flaps in and out with respiration, which is stertorous, and a positive Babinski sign is obtained on the hemiplegic side. Where lesser degrees of coma exist, a unilateral diminution or abolition of the corneal reflex is of value in distinguishing apoplexy from other conditions. Where the pupils are unequal, it is always well to remember that the larger pupil is usually on the side of the haemorrhage. Syphilis must always be kept in mind as a cause of cerebral thrombosis. Cerebral embolism is suggested by the presence of heart disease such as mitral stenosis and auricular fibrillation. Pontine haemorrhage results in homolateral cranial nerve palsy and contralateral hemiplegia, but all four limbs are soon paralysed as a rule. A high temperature and pin-point pupils further characterize this condition. In my experience, subarachnoid haemorrhage, the 'apoplexy of young people,' has been the commonest individual disorder amongst the cerebral vascular accidents admitted during the past year. The diagnosis is seldom difficult. Neck rigidity is the outstanding feature as a rule, but in some deeply comatose patients, this is absent, and the diagnosis is only apparent on lumbar puncture. Retinal haemorrhages, usually near the disc, vitreous and subhyaloid haemorrhages, papilloedema, and 3 rd and 6th nerve palsies with resultant squint, are occasional features of a subarachnoid haemorrhage. Frequently, bilateral extensor plantar responses are obtained. The urine may contain sugar and albumin, and a rise of temperature up to 100 is a common finding.

Hypertensive encephalopathy should be thought of in the comatose patient with an extremely 
high blood pressure, e.g., 250/150. There may be slight neck rigidity, but lumbar puncture reveals a clear fluid under high pressure. Changes in the fundi depend on whether the hypertension has been long standing or not, and range from slight arteriovenous kinking to papilloedema and retinal haemorrhages. Similarly, the urine may be normal, or contain albumin and casts.

\section{Case Report}

A male aged $5 \circ$ years was admitted on October 30, 1947. The history, obtained from an outside source, was that for two weeks the patient had been complaining of headaches and had vomited several times. On the day of admission, shortly before becoming unconscious, he had complained of sudden blindness. Examination revealed a heavily built man, semicomatose, pale skin and slight puffiness of the eyelids. A faintly uriniferous smell from the breath was noted. The pupils were equal and light reactive. There was slight bilateral papilloedema and evidence of arteriovenous kinking on examination of the fundi.

Reflexes present and equal in upper and lower limbs. Doubtful bilateral extensor plantar responses. Moderate neck rigidity. Lungs normal. heart sounds normal. Blood-pressure 240/130. Pulse 65. Temperature $98^{\circ}$. Lumbar puncture revealed a clear fluid under a pressure of $300 \mathrm{~mm}$. of water. The pressure was $\mathrm{r}^{\circ}$ duced to $80 \mathrm{~mm}$., venesection was performed, and a few hours after admission the patient was conscious, though complaining of blindness. Urine examination revealed a dense cloud of albumin, numerous red blood cells, and moderate numbers of cellular casts. Blood urea $5 \mathrm{I} \mathrm{mgm}$. per cent. He rapidly improved, and in a further 48 hours his sight was restored. On discharge from hospital his bloodpressure was $150 / 100$, but his blood urea was 42 mgm. per cent. and his urine contained albuminuria and casts, indicating permanent and severe renal damage with a poor prognosis.

\section{Diabetic and Hypoglycaemic Coma}

It is surprising how often these two conditions are misdiagnosed in practice, the more so when it is remembered that if in doubt, an intravenous injection of glucose will produce a dramatic recovery if the coma is due to hypoglycaemia, and will do no immediate harm if it is due to hyperglycaemia. A smell of acetone from the breath, a dry skin, air hunger, soft eyeballs, flaccid muscles, depressed reflexes and flexor plantar responses characterize diabetic coma. The urine, obtained by catheterization, is loaded with sugar and acetone. In hypoglycaemic coma, the eyeball tension is normal, there is profuse sweating and the plantar responses are extensor. The temperature is always either normal or subnormal in uncomplicated cases of either condition. It is well to remember that although a comatose patient is a known diabetic, the diagnosis is not always one of hyper- or hypo-glycaemia.

\section{Case Report}

A male, aged 54, a known diabetic, was admitted on December 5,1947 , in a deep coma. He manifested shallow rapid respirations, sweating, normal eyeball tension and bilateral extensor plantar responses. The urine contained a slight trace of sugar, and no acetone. Blood sugar $85 \mathrm{mgm}$. per cent. He had however, a temperature of $100^{\circ}$, and a slightly stiff neck. Lumbar puncture revealed a clear fluid with excess of cells (37 per cu. mm.mostly polymorphs), normal sugar content, normal protein, chloride $700 \mathrm{mgm}$. per cent. Culture sterile. A chest X-ray revealed bilateral pulmonary tuberculosis, not apparent on clinical examination. The patient died on December 13, 1947, and at post-mortem the presence of tuberculous meningitis was confirmed.

There are rare cases of diabetic coma where sugar is absent from the urine, the explanation being that the patient was suddenly deprived of carbohydrate and the fat metabolism became so disordered that coma resulted. Similarly, there are cases where the urine may contain much sugar and albumin, but no acetone, and yet the breath may smell strongly of acetone. In such cases there is renal failure, casts will be found in the urine and the blood urea is raised. Hypoglycaemic coma may be prolonged and fatal, as in a case described by Winkler, where after an initial response to intravenous glucose, relapse occurred and the patient died nine days later, without having regained consciousness. In this case, protamine zinc insulin had been given by the practitioner, who mistakenly diagnosed diabetic coma. Where no history of insulin administration can be obtained, the possibility of an islet celled tumour of the pancreas must be kept in mind.

\section{Case Report}

A female aged 39 was admitted unconscious on March 23, 1948, with no history available. She was semicomatose-pupils equal and light reactive, corneal reflexes present, fundi normal, profuse sweating, bilateral extensor plantar responses.

Heart and lungs normal. Blood-pressure $120 / 70$. Lumbar puncture normal. U'rine normal. Blood sugar $43 \mathrm{mgm}$. per cent. Blood urea $30 \mathrm{mgm}$. per cent.

A 5 per cent. dextrose drip was commenced, and two hours later she partially regained concious- 
ness, only to relapse again and become more deeply comatose than before. The dextrose drip was continued and $20 \mathrm{cc}$. of 50 per cent. glucose given intravenously with no effect. The blood sugar was now $100 \mathrm{mgm}$. per cent.

The patient remained unconscious for nine days, during which time, aneurin, riboflavin, nicotinic acid, and glucose were given in large amounts, and her blood urea and blood sugar levels remained within normal limits. There were no localizing nervous signs and the fundi remained normal. On regaining consciousness, she was aphasic, and did not recover the power of speech until April 21, I948. Fasting blood sugars on the $15^{\text {th }}$, 20th, 23rd and 24th of April were 43, 40, 40 and $37 \mathrm{mgm}$. per cent. respectively. An exploratory laparotomy was advised to ascertain if an islet celled tumour of the pancreas was present, but the patient took her own discharge against advice.

(This patient was readmitted to hospital on July I4, 1948, comatose with a blood sugar of 20 mgm. per cent. At operation on July 16, 1948, a benign adenoma of the tail of the pancreas was successfully removed. The patient made an uneventful recovery.)

Cerebral damage is well known to occur following prolonged hypoglycaemia, and presumably this is the explanation of the aphasia, which took three weeks to clear up.

\section{Infections}

Coma due to meningitis, encephalitis, fulminating septicaemias, malaria, pneumonia etc. and as a terminal phenomenon in the course of almost any severe infection, is not infrequently seen.

\section{Case Report}

A female aged 6o was admitted on March 22, 1948. A history obtained from the relatives stated that the patient was well until the morning of March 21, 1948, when she complained of headache and refused her food. She retired to bed, and became delirious towards evening. Examination revealed a pale, restless and resistive, semicomatose patient. Temperature $\mathrm{roI}^{\circ}$. Pulse 100 . There was marked neck rigidity and a diffuse purpuric eruption on the trunk and limbs.

Lumbar puncture revealed an opaque fluid, and microscopy showed the presence of gram negative intracellular diplococci.

The patient made a good recovery with combined penicillin and sulphamezathine therapy.

This case illustrates the rapidity of onset of coma in an acute fulminating meningococcal meningitis.
Somnolence and stupor are more characteristic 3 of encephalitis than deep coma. Lumbar puncture $\stackrel{D}{\perp}$ reveals a clear fluid with excess cells, often lymph-.. ocytes, and in contrast with pyogenic infections, $\overrightarrow{\vec{B}}$ the sugar content is normal or increased. Cerebral $\stackrel{\oplus}{\rightarrow}$ malaria due to the malignant tertian parasite should be thought of in the case of a comatose hyperpyrexial patient who is known to have $\frac{{ }^{\circ}}{\widehat{D}}$ returned from an endemic area within a year. $\unrhd$ The parasites may be difficult to find in blood क films, but the finding of intracellular melanin pig- $\overrightarrow{0}$ ment in the cells of the cerebrospinal fluid is diagnostic. The difficulties in the diagnosis of coma $\vec{\omega}$ due to infection are illustrated by the following case.

\section{Case Report}

A male aged 2 I was admitted on April 21, I948. N The only history available was that the patient $\infty$ was quite well at breakfast, went upstairs, and $\mathcal{G}^{2}$ was found unconscious 20 minutes later. $\mathrm{He} O$

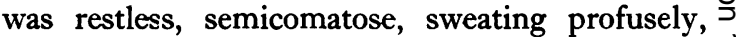
with rapid bubbly respirations. Temperature $102^{\circ}$. $\vec{\square}$ Pulse ro4. Pupils equal and light reactive, right $\mathbb{D}$ external rectus palsy, moderate neck rigidity, all $\stackrel{\infty}{\square}$ reflexes present and equal, lower limbs rather spastic, bilateral extensor plantar responses. Lungs - diffuse moist sounds. Heart-loud apical syste $\vec{\varphi}$ lic murmur, and systolic and diastolic murmuss $\infty$ heard close to the sternum. No oedema or ent gorgement of the neck veins. Lumbar puncture revealed a cloudy fluid with 470 polymorphs per cu. mm. but no organisms. The patient died a few hours after admission.

Post-mortem examination revealed mitral stenosis with large friable vegetations on the anterior cusp of the valve. Infarcts present in the spleen and kidneys. The brain was congested, but showed no other naked eye abnormality.

Multiple microscopic cerebral emboli undoubtedly occurred in this case, with resultant coma, and excess polymorphs in the cerebro-spinal fluid.

\section{Miscellaneous Causes of Goma}

(I) Uraemia. A raised blood-presșure, albumin and casts in the urine, and retinal changes, e.g. $\frac{T}{0}$ albuminuric retinitis, suggest uraemia. A careful examination of the abdomen will sometimes dis- م close congenital cystic kidneys, or a distended $N$ bladder. Rectal examination to ascertain if the N prostate is enlarged should never be omitted.

(2) Cerebral tumour and cerebral abscess. Diagnosis may be extremely difficult. Cerebral abscess is usually a complication of middle ear disease or $\stackrel{D}{\mathcal{D}}$ chronic pulmonary infection such as bronchiectasis or empyema. If during the course of examination, 0 marked bilateral papilloedema is found, caution 
should be observed with regard to lumbar puncture.

(3) Heart disease. It is frequently forgotten that in congestive cardiac failure, the brain suffers from venous engorgement. Coma from this cause is usually obvious. In Stokes-Adams syndrome, the duration of unconsciousness is brief as a rule, and the extremely slow or absent pulse is diagnostic.

(4) Epilepsy. A history of 'grand mal' is usually obtained, and the duration of the stage of flaccid coma is brief. Evidence of tongue biting and urinary incontinence should be looked for.

(5) Hysteria. The general attitude of the patient, forced closure of the eyelids, normal pupillary reflexes and normal deep reflexes with flexor plantar responses, usually leave the examiner in no doubt as to the correct diagnosis.

(6) Dementia praecox (schizophrenia). The sudden onset of a stuporose state can apparently be the first manifestation of this disease.

\section{Case Report}

A female aged 26 was admitted in a stuporose condition on April 27, I948. Her parents stated that she had been in good health until two hours before admission, when they found her unconscious in her bedroom. Examination revealed a well-built female, colour normal, respirations normal, skin moist. There was diminished response to painful stimuli. The jaw was kept tightly clenched. Pupils equal and light reactive. Corneal reflexes present. Fundi normal. She was generally resistive, the arms and legs were held stiffly, and neck flexion was resented. Deep reflexes present and equal. Plantar responses flexor. Temperature $98^{\circ}$. Pulse 6o. Heart and lungs normal. Bloodpressure $120 / 70$. Urine examination normal. She remained in a stuporose and resistive condition for 48 hours, during which time repeated physical examinations were made. The persistent spasm of the jaw was most noticeable. Lumbar puncture revealed a clear fluid under normal pressure. Laboratory examination revealed no abnormality. Blood sugar normal.

On the afternoon of April 29, I948, she became wide awake; sat up in bed, but did not speak or answer questions. Shortly afterwards she was found out of bed and refused to get back. She now answered questions, but gave confused replies, and appeared to think she was attending lectures and clinical demonstrations at a medical school. She insisted on helping the ward sister to write out her reports.

It transpired that this girl was a first-year medical student who had been studying very hard for some weeks prior to admission. Thère was no previous history of mental illness. A psychiatric specialist kept her under observation for the next two days, and had no hesitation in diagnosing schizophrenia of acute onset, with catatonic stupor.

\section{Vitamin Deficiency}

Chronic alcoholism, carcinoma of the stomach or oesophagus, and diarrhoeal diseases such as ulcerative colitis, predispose to deficiency of thiamine and nicotinic acid. A stuporose or semicomatose patient with pupillary abnormalities or nystagmus, evidence of peripheral neuritis, cogwheel rigidity of the extremities, and grasping and sucking reflexes, should suggest the possibility of Wernicke's encephalopathy. Avery Jones and Robinson have described an interesting case of this kind, closely simulating diabetic coma, where the diagnosis of Wernicke's encephalopathy was confirmed post-mortem. They postulated injury to the hypothalamic area by a minute haemorrhage as the cause of the hyperglycaemia.

\section{Cerebral Emboli from Malignant Disease}

Under the descriptive heading, coma carcinomatosum, Purves-Stewart mentions the development of coma in patients dying from visceral cancer " with secondary malignant deposits. Occasionally the meninges become infiltrated with malignant cells, and the latter can be found in the cerebrospinal fluid.

Coma must be a most unusual presenting feature of a carcinoma of the stomach, but such was the case in the following instance.

\section{Case Report}

A female aged 68 was admitted on December I 5, I947. Her landlady stated that for some weeks the patient had complained of indigestion and had only been able to eat 'sloppy' foods. She was found unconscious on the floor of her room a few hours prior $t^{\wedge}$ admission.

Examination revealed a wasted elderly woman with no obvious cyanosis or dyspnoea. Temperature $97^{\circ}$. Pulse 96 . She was semicomatose, pupils equal and light reactive, corneal reflexes present, arteriosclerotic changes in both fundi. Normal upper limb reflexes. Absent ankle jerks lower limbs. A right extensor plantar response was obtained. Lungs, heart and abdomen normal. Blood-pressure 1 I0/65.

Thickened arteries palpable in both upper limbs. Slight oedema of the ankles.

Lumbar puncture revealed a clear fluid under normal pressure, but microscopy revealed excess cells of a peculiar type (59 per cu. mm.). . They were large and granular, with one and sometimes two eccentric nuclei. Some showed evidence of mitosis. Sternal puncture was performed, but 
revealed no abnormality. A blood-count was normal except for a slight leucocytosis (I I,000 white cells; polymorphs 88 per cent.).

The patient remained unconscious, neck rigidity developed, both plantar responses became extensor, and prior to her death on December i9, 1947, the cerebrospinal fluid pressure rose to 220 $\mathrm{mm}$. and the temperature to $\mathrm{I}^{\circ} 3^{\circ}$.

Post-mortem examination revealed a carcinoma of the stomach (papillary and trabecular on section) with secondary deposits in the adjacent lymph glands and right suprarenal. There was carcinomatous infiltration of the meninges over the cerebrum and cerebellum.
Hepatic coma is usually a terminal event in the course of severe liver disease such as cirrhosis.

Exsanguination as a cause of coma is clinically obvious.

\section{BIBLIOGRAPHY}

AVERY JONES, F., and ROBINSON, V. C. (1947), Lancet, 2, 907. PURVES-STEWART, Sir James (1947), 'The Diagnosis of Nervous Diseases.' p.I53.

WALSHE, F. M. R. (1947), 'Diseases of the Nervous System.' p.ro4. WINKLER, J. L. (1948), Lancet, 1, 215.

\section{ACKNOWLEDGMENT}

I wish to thank Dr. T. Robson and Dr. J. H. Bentley for permission to publish details of these cases.

\section{BOOKS RECEIVED}

\section{The Editorial Board acknowledge with thanks the receipt of the} following volumes. A selection from these will be made for review.

'Progress in Clinical Medicine.' Edited by Raymond Daley, M.A., M.D., M.R.C.P., and Henry G. Miller, M.D., M.R.C.P., D.P.M. Pp. xi +356 . With 22 figures and 15 plates. J. \& A. Churchill, London. I948. 2is.

'Osteo-Arthritis of the Hip-Joint.' By $\mathrm{H}$. Warren Crowe, D.M., B.Ch., M.R.C.S., L.R.C.P. Pp. viii +70 . With 24 plates. George Pulman \& Sons, Ltd. Distributed by Rolls House Publishing Co., Ltd., London. I 948 . 35s. 6d.

'Human Embryology and Morphology.' By Sir Arthur Keith. 6th Edition. Pp. xii +690 . With 578 figures. Edward Arnold, London. 1948. 40s.

'The National Health Service Act, 1946.' By S. R. Speller, Ll.B. Pp. xc + 497. H. K. Lewis \& Co., London. I948. $42 \mathrm{~s}$.

' Critical Studies in Neurology.' By F. M. R. Walshe, M.D., F.R.S. Pp. xv + 256. With 16 illustrations. E. \& S. Livingstone, Edinburgh. 1948. I 5 s.

' Eden and Holland's Manual of Obstetrics.' By Alan Brews, M.D., M.S., M.R.C.P., F.R.C.S., F.R.C.P.G. 9th Edition. Pp. xii +796 . With 405 illustrations and 36 plates, 12 in colour. J. \& A. Churchill, London. I $948.42 \mathrm{~s}$.

' Obstetrics and Gynaecology.' By Beatrice M. Willmott Dobbie, M.A., M.B., F.R.C.S., D.M.R.E. Pp. xi +358 . With 22 illustrations. H. K. Lewis, London. I948. 20 s.

' The Medical Annual I 948 (66th Issue).' Edited by Sir Henry Tidy, K.B.E., M.A., M.D., F.R.C.P. and A. Rendle Short, M.D., B.S., B.Sc., F.R.C.S. Pp. xii +414 . With 56 plates. John Wright $\&$ Sons, Bristol. Simpkin Marshall, London, 1948. 22s. $6 \mathrm{~d}$.
'Demonstrations of Physical Signs in Clinical Surgery. Part III.' By Hamilton Bailey, F.R.C.S., F.A.C.S., F.I.C.S., F.R.S.E. I Ith Edition. Pp 108. With many illustrations, some in colour John Wright \& Sons, Bristol. Simpkin Marshallo London. I948. 8s. 6d. per part.

' Clinical Endocrinology.' By Laurence Martin, M.D., F.R.C.P., and Martin Hynes, M.D., M.R.C.P. Pp. viii +222 . With 8 plates and 22 text figures. J. \& A. Churchill, London. I948. I5s.

'Recent Advances in Respiratory 'Tuberculosis.' By Frederick Heaf, M.A., M.D., F.R.C.P. and N. Lloyd Rusby, M.A., D.M., F.R.C.P. 4th Edition. Pp. vii +290 . With 5 plates and 7 text figures. J. \& A. Churchill, London. 1948. 2is.

' The Natural Development of the Child.' By Agatha H. Bowley, Ph.D. 3rd Edition. Pp. xvi + I 90. With 84 photographic illustrations. E. \& S. Livingstone, Edinburgh. 1948. 8s. 6d.

' Notes on Infant Feeding.' By G. B. Fleming, M.D., F.R.C.P., F.R.F.P.S. and Stanley Graham, M.D., F.R.C.P.(Ed.), F.R.F.P.S. 3rd Edition. Pp. 66. E. \& S. Livingstone, Edinburgh. 1948. 3 s.

'A Surgeon's Guide to Local Anaesthesia.' By C. E. Corlette, M.D., Ch.M., F.R.A.C.S. Pp. xi 355. With 200 illustrations. John Wright \& Sons, Bristol. Simpkin Marshall (I 94I), London. I 948. $35 \mathrm{~s}$.

'Viral and Rickettsial Infections of Man.' Edited by Thomas M. Rivers, M.D., Director of the Hospital, The Rockefeller Institute for Medical Research, New York. Pp. xvi + 587. With 77 illustrations, 6 being colour plates. J. B. Lippincott \& Co. 1948. 45 s. 